\title{
1.|||||||||||||||||||||||||||||||||||||||||||||||||||||||||||||||||||||||.
}

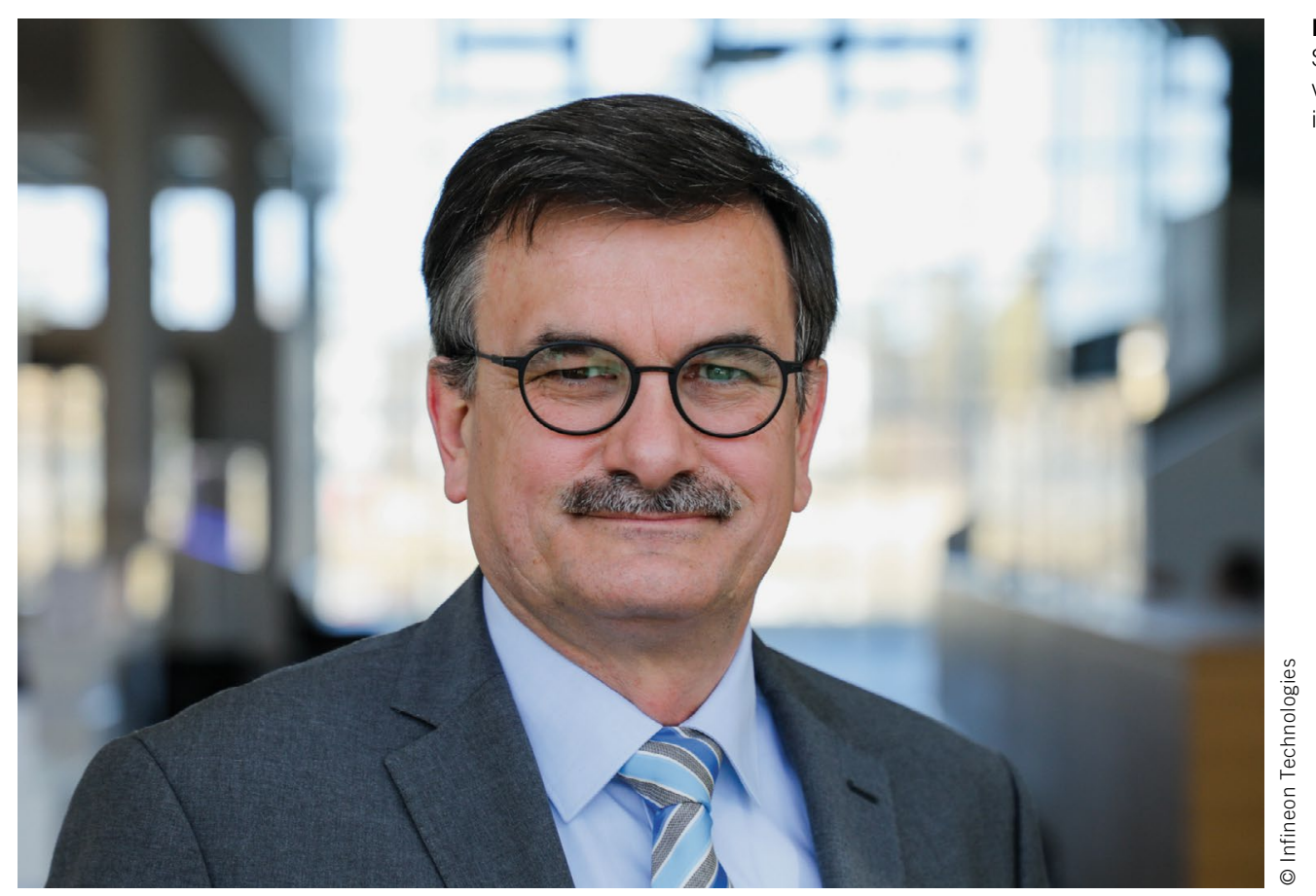

Hans Adlkofer

Senior Vice President Automotive von Infineon Technologies in Neubiberg

\section{Sicherheit braucht Hardware}

Coronabedingt weist die Statistik für im Straßenverkehr getötete Menschen 2020 in Deutschland einen Rückgang um 322 auf: Das ist erfreulich. Aber machen wir uns nichts vor, von einer Vision Zero, wie sie der Verkehrsclub Deutschland e. V. 2009 ausgerufen hat, sind wir noch weit entfernt. Trotz Sicherheitsgurt, Airbag, ABS und neuen Helfern wie Notbremsassistent stagniert die Anzahl der Verkehrstoten in den letzten vier bis fünf Jahren auf einem hohen Niveau. In einigen Ländern steigen die Zahlen sogar wieder leicht. 2724 Tote allein in Deutschland sind 2724 zu viel. Um die Vision Zero Wirklichkeit werden zu lassen, brauchen wir deshalb ein Mehr an Sicherheit - Safety und Security, um genau zu sein. Dabei hilft uns, dass der persönliche Individualverkehr an der Schwelle zu einer Revolution steht. Dies sollten wir nutzen, denn mit der Einführung neuer Fahrerassistenzsysteme (ADAS) und dem autonomen Fahren (AD) im Blick kann uns die Vision Zero gelingen.

Ein wesentlicher Baustein für ADAS und für AD ist Sensorik. Im Bereich der Personen- sowie Nutzfahrzeuge verlassen wir uns schon seit Dekaden auf unterschiedliche Sensorlösungen wie Radar sowie beginnend vereinzelt Lidarsysteme. Erst kürzlich wurde ein elektromechanisches Mikrosystem (MEMS) für Mikrofone vorgestellt, das auch im Außenbereich von Fahrzeugen eingesetzt werden kann. Mikrofone als Erweiterung unserer Sinne können damit nicht mehr nur als Basis von Sprachassistenten das Leben der Fahrenden einfacher machen. Sie verbessern nun auch die Sicherheit, denn nicht nur Einsatzfahrzeuge wie Rettungswagen oder Feuerwehr werden damit deutlich früher wahrgenommen.

Die Halbleiterindustrie entwickelt fortwährend neue hardwarebasierte Lösungen, die dem Fahrzeug zusätzliche Sinne verleihen und dieses sicherer machen. Und das ist mit zunehmender Komplexität im Straßenverkehr aufgrund der immer stärkeren Nutzung der Verkehrswege durch unterschiedlichste Teilnehmer auch notwendig. Wir brauchen Sensoren zur Unterstützung der Fahrzeuge, damit externe Ereignisse oder Situation eindeutig erkannt und die richtigen Maßnahmen ergriffen werden können, um einen Unfall zu vermeiden.

Darüber hinaus ist es zur Früherkennung von gefährlichen Situationen notwendig, Fahrzeuge sicher zu vernetzen - mit der Infrastruktur und anderen Fahrzeugen. So werden nicht nur Einsatzfahrzeuge in der Nähe erkannt, sondern auch Informationen über Glatteis oder kritische Fahrsituationen wie zum Beispiel eine Notbremsung. Mithin Gefahren, die nicht unbedingt im Erkennungsfeld der klassischen Sensorik liegen. Die Vernetzung setzt aber Datensicherheit zwingend voraus, auch hierfür gilt: „No safety without security“. Denn kompromittierte Daten ganz gleich ob über einen bewussten Angriff oder ein fälschlich eingespieltes Update - stellen eine Gefahr für die Sicherheit dar.

Ich bin sehr zuversichtlich, dass wir mit dem sinnvollen Zusammenschluss von Sensoren in einem Gesamtsystem Auto und der Absicherung mit Security-Chips die Vision Zero wahr werden lassen können. Auf Basis von Hardware. 